\title{
OPTIMASI BIAYA PENGIRIMAN TELUR AYAM MENGGUNAKAN PENDEKATAN MODEL TRANSPORTASI NWC DAN SOFTWARE LINGO
}

\author{
Dandi Nurdiansyah ${ }^{1}$, Diva Maulana ${ }^{2}$, Artia Tresnadi $^{3}$, Muchammad Fauzi $^{4}$ \\ 1,2,3,4) Program Studi Teknik Industri, Fakultas Teknik Universitas Widyatama \\ Email: nurdiansyahdandi98@gmail.com ${ }^{1}$, maulanadiva89@gmail.com ${ }^{2}$, artia.uuh@gmail.com ${ }^{3}$, \\ muchammad.fauzi@widyatama.ac.id ${ }^{4}$
}

\begin{abstract}
Distribution of goods from producers to consumers becomes one aspect of running a business that must be planned and taken into account to meet the market's needs. Delivery of goods results in costs incurred and is one of the obstacles often faced. Problems in the distribution of goods include the amount of inventory, the amount of consumer demand, the distance traveled, and the costs during the delivery process. This study describes optimal postage with transportation methods to generate maximum efficiency costs. The problem faced in this case using the North West Corner (NWC) method, then the results of the data obtained were tested optimized using LINGO software. Before the research was conducted, the cost of postage incurred by the company was Rp.278.000. The research results obtained after applying the NWC is Rp.255.000, and the LINGO software method is Rp.240.000. This research aims to get optimal costs on the distribution of chicken eggs to increase cost savings at Ayam Sehat.com Shop in Cimahi. Using the NWC method, in this case, can result in smaller distribution costs than before, then this NWC method can be applied to the Ayam Sehat.com shop.
\end{abstract}

Keywords: distribution, cost, efficiency, NWC method

\section{Abstrak}

Pendistribusian barang dari produsen hingga sampai ketangan konsumen menjadi salah satu aspek dalam menjalankan suatu usaha yang harus direncanakan dan diperhitungkan demi memenuhi kebutuhan pasar. Pengiriman barang mengakibatkan adanya biaya yang timbul dan merupakan salah satu kendala yang sering dihadapi. Permasalahan dalam pendistribusian barang diantaranya jumlah persediaan, jumlah permintaan konsumen, jarak yang ditempuh dan biaya yang keluar saat proses pengiriman. Penelitian ini menjelaskan tentang memperhitungkan ongkos kirim yang optimal dengan metode transportasi untuk menghasilkan biaya efesiensi yang maksimal. Masalah yang dihadapi pada kasus ini menggunakan metode North West Corner $(N W C)$, kemudian hasil data yang diperoleh diuji keoptimalannya menggunakan software LINGO. Sebelum penelitian dilakukan, biaya ongkos kirim yang dikeluarkan oleh perusahaan ialah sebesar Rp.278.000. Hasil penelitian yang diperoleh setelah menerapkan metode NWC adalah sebesar Rp.255.000 dan Software LINGO ialah sebesar Rp.240.000 Tujuan penelitian ini adalah untuk mendapatkan biaya optimal pada pendistribusian telur ayam untuk meningkatkan penghematan biaya pada Toko Ayam Sehat.com di kota Cimahi. Menggunakan metode $N W C$ pada kasus ini dapat menghasilkan biaya distribusi lebih kecil daripada sebelumnya, maka metode NWC ini dapat diterapkan pada Toko Ayam Sehat.com tersebut.

Kata Kunci: distribusi, biaya, efisiensi, metode North West Corner (NWC).

Received: June 30, 2021 / Accepted: December 01, 2021 / Published Online: December 30, 2021 
Jurnal Lebesgue: Jurnal Ilmiah Pendidikan Matematika, Matematika dan Statistika

Dandi Nurdiansyah, Diva Maulana, Artia Tresnadi, Muchammad Fauzi

Volume 2, No. 3, Desember 2021 hal.234-244

DOI Artikel: 10.46306/lb.v2i3.77

\section{PENDAHULUAN}

Kebutuhan primer merupakan kebutuhan yang harus dipenuhi dan tidak dapat ditinggalkan, salah satunya adalah kebutuhan makanan. Sumber makanan diperoleh dari alam yang kemudian di olah oleh produsen yang kemudian disalurkan kepada masyarakat sebagai konsumen. Setiap perusahaan pelaku modal usaha didirikan dengan tujuan untuk memperoleh keuntungan, termasuk juga Toko Ayam Sehat selaku penyedia telur ayam untuk keperluan konsumsi masayarakat. Untuk mencapai tujuan tersebut perusahaan tentu harus memperhitungkan seluruh biaya yang digunakan untuk tetap seimbang antara pemasukan dan pengeluaran perusahaan agar laba yang dihasilkan bisa optimal. Salah satu biaya yang harus diperhatikan ialah biaya dalam proses distribusi. Biaya distribusi merupakan biaya yang mutlak yang harus dikeluarkan oleh perusahaan.

Masalah transportasi pada dasarnya membahas tentang distribusi barang dari sumber ke sejumlah tujuan yang ada, dengan adanya beberapa rute yang harus ditempuh dengan meminimalkan ongkos angkut secara keselurhan. Pengiriman barang dari perusahaan ke beberapa tempat tujuan membutuhkan alat transportasi. Toko Ayam Sehat.com menggunakan alat transportasi milik sendiri berupa mobil pick up dalam operasional pendistribusian telur ayam. Biaya ongkos kirim pendistribusian telur dari toko ayam sehat.com perbulan Januari 2021 adalah sebesar Rp 278.000. Berdasarkan hal tersebut diperlukan perhitungan untuk efisiensi biaya transportasi dengan menggunakan metode $N W C$ pada Toko Ayam Sehat.com sebagai solusi awal dan menggunakan software LINGO sebagai solusi akhir.

Penelitian ini bertujuan untuk mencari dan menyelesaikan optimasi biaya pengiriman telur ayam tingkatan pedagang grosir ke beberapa pasar yang ada di kota Cimahi dan Bandung, sehingga terpenuhi semua kebutuhan permintaan dengan jumlah biaya transportasi yang serendah mungkin untuk mencapai keuntungan yang sebesar-besarnya. Distribusi telur ayam dari toko ke beberapa pasar tujuan bisa dihitung menggunakan metode transportasi North West Corner $(N W C)$. Metode transportasi sangat dibutuhkan oleh Toko Ayam Sehat.com karena selama ini toko tersebut belum pernah menerapkan metode ini sebelumnya, sehingga akan sangat berguna bagi toko agar dalam pendistribusian barang menjadi lebih efektif dengan ongkos kirim yang dapat diminimalkan. 
Jurnal Lebesgue: Jurnal Ilmiah Pendidikan Matematika, Matematika dan Statistika

Dandi Nurdiansyah, Diva Maulana, Artia Tresnadi, Muchammad Fauzi

Volume 2, No. 3, Desember 2021 hal.234-244

DOI Artikel: 10.46306/lb.v2i3.77

\section{METODE PENELITIAN}

\section{Pengumpulan Data}

Pengumpulan data penelitian ini dilakukan dengan survey lokasi dan wawancara untuk memenuhi data primer yang dibutuhkan dalam pengelolaan data. Praktikan melakukan pengumpulan data dengan cara berkunjung langsung ke lokasi usaha serta mengajukan beberapa pertanyaan yang berhubungan dengan data yang diperlukan terkait penelitian biaya pengiriman yaitu data ongkos pengiriman, supply dari gudang dan Demand dari tiap pasar tujuan secara tatap muka dengan pemilik toko Bapak Haji Dadang Koswara. Selanjutnya, dilakukan observasi lapangan secara langsung dengan mengamati dan mengumpulkan data yang diperlukan terkait penelitian biaya pengiriman telur ayam di gudang penyimpanan telur ayam dan di beberapa lokasi pasar yang dijadikan sasaran penjualan oleh toko Ayam Sehat.com.

\section{Metode Transportasi}

Metode transportasi merupakan suatu metode yang digunakan untuk mengatur distribusi dari sumber-sumber yang menyediakan produk yang sama, ke tempat-tempat yang membutuhkan secara optimal. Alokasi produk ini harus diatur sedemikian rupa, karena terdapat perbedaan biaya-biaya alokasi dari satu sumber ke tempat-tempat tujuan berbeda-beda, dan dari beberapa sumber ke tempat-tempat tujuan juga berbeda-beda (Subagyo et al. 1990). Permasalahan transportasi termasuk permasalahan program linier yang khusus yang dapat diselesaikan dengan metode transportasi yang dibuat dalam sebuah model tertentu kemudian diselesaikan dalam perhitungan.

\section{Metode North West Corner (NWC)}

Metode North West Corner adalah metode paling sederhana pada metode transportasi untuk mencari solusi awal. Langkah-langkahnya dapat diringkas sebagai berikut (Mulyani, 2007)

1. Mulai pada pojok barat laut tabel dan dialokasikan sebanyak mungkin pada tabel bagian sudut kiri atas tanpa menyimpang dari kendala penawaran atau permintaan (artinya X11 ditetapkan sama dengan yang terkecil diantara nilai S1 dan D1)

2. Ini akan menghabiskan penawaran pada sumber 1 dan atau permintaan pada tujuan 1 . Akibatnya, tak ada lagi barang yang dapat dialokasikan ke kolom atau baris yang telah dihabiskan dan kemudian baris atau kolom itu dihilangkan. Kemudian alokasikan sebanyak mungkin ke kotak di dekatnya pada baris atau kolom yang tak dihilangkan. Jika kolom maupun baris telah dihabiskan, pindahlah secara diagonal ke kotak berikutnya. 
Jurnal Lebesgue: Jurnal Ilmiah Pendidikan Matematika, Matematika dan Statistika

Dandi Nurdiansyah, Diva Maulana, Artia Tresnadi, Muchammad Fauzi

Volume 2, No. 3, Desember 2021 hal.234-244

DOI Artikel: 10.46306/lb.v2i3.77

3. Lanjutkan dengan cara yang sama sampai semua penawaran telah dihabiskan dan keperluan permintaan telah dipenuhi.

Model matematis North West Corner (NWC) secara umum adalah sebagai berikut:

$\operatorname{Min} \sum_{i=1}^{m} \sum_{j=1}^{n}$ CijXij (biaya transportasi total)

Dengan kendala:

$\sum_{j=1}^{n} X i j=S i($ penawaran/supply)

$\sum_{j=1}^{m} X i j=S i($ permintaan $/$ demand $)$

$X i j \geq 0, i=1, \ldots, n, j=1, \ldots, m$

\section{Software Lingo}

Software LINGO adalah perangkat lunak komprehensif yang dirancang dengan cara yang dapat membantu dalam mengoptimalkan, menganalisis, dan memecahkan masalah pemrograman linier dan non-linear (cembung, non-convex atau global), kuadratik, pembatas kuadratik, kerucut orde dua, stokastik dan model optimasi integer. Perangkat lunak ini disertai dengan bahasa pemodelan optimasi yang mudah dan dapat dipahami. Software lingo digunakan untuk melihat solusi optimal dari permasalahan transportasi yang dicari dan sebagai pembanding hasil yang didapat dari metode North West Corner. (inc., Lindo System, 2020)

\section{HASIL DAN PEMBAHASAN}

Optimasi biaya transportasi yang dilakukan oleh praktikan menggunakan metode North West Corner (NWC) untuk mengetahui solusi awal biaya pada bulan Januari 2021. Toko Ayam Sehat.com memasok telur ayam ke 3 pasar terdekat yaitu Pasar Ciroyom, Pasar Caringin dan Pasar Antri. Biaya pengiriman dari gudang ke pasar berbeda-beda tergantung dengan jarak yang ditempuh. Data permintaan dan pasokan toko Ayam Sehat.com pada bulan Januari 2021 tersaji pada tabel 1 dan tabel 2 berikut: 
Jurnal Lebesgue: Jurnal Ilmiah Pendidikan Matematika, Matematika dan Statistika

Dandi Nurdiansyah, Diva Maulana, Artia Tresnadi, Muchammad Fauzi

Volume 2, No. 3, Desember 2021 hal.234-244

DOI Artikel: 10.46306/lb.v2i3.77

Tabel 1. Data Persediaan Telur Ayam Perbulan Januari 2021

\begin{tabular}{cccc} 
No & $\begin{array}{c}\text { Tempat } \\
\text { Penyimpanan }\end{array}$ & Jumlah & Satuan \\
\hline 1 & Cimahi & 6500 & Butir \\
\hline 2 & Batujajar & 4500 & Butir \\
\hline 3 & Lagadar & 4000 & Butir \\
\hline & Total & 15000 & Butir \\
\hline
\end{tabular}

Tabel 2. Data Permintaan Telur Ayam Perbulan Januari 2021

\begin{tabular}{cccc} 
No & $\begin{array}{c}\text { Tempat } \\
\text { Penyimpanan }\end{array}$ & Jumlah & Satuan \\
\hline 1 & Pasar Ciroyom & 7000 & Butir \\
\hline 2 & Pasar Caringin & 5000 & Butir \\
\hline 3 & Pasar Antri & 3000 & Butir \\
\hline & Total & 15000 & Butir \\
\hline
\end{tabular}

Data ongkos transportasi persatuan yang tercantum pada tabel 1 dan tabel 2 adalah rupiah perbutir dari setiap tempat penyimpanan ke setiap pasar tujuan dapat dilihat pada tabel 3 berikut:

Tabel 3. Data Supply dan Demand Telur Ayam Pada Bulan Januari 2021

\begin{tabular}{|c|c|c|c|c|}
\hline \multirow{2}{*}{ Sumber } & \multicolumn{3}{|c|}{ Tujuan Pengiriman } & \multirow{2}{*}{$\begin{array}{l}\text { Supply } \\
\text { (Butir) }\end{array}$} \\
\hline & $\begin{array}{c}\text { Pasar Ciroyom } \\
\text { Rp/butir }\end{array}$ & $\begin{array}{c}\text { Pasar Caringin } \\
\text { Rp/butir }\end{array}$ & $\begin{array}{l}\text { Pasar Antri } \\
\text { Rp/butir }\end{array}$ & \\
\hline Cimahi & 15 & 20 & 10 & 6500 \\
\hline Batujajar & 25 & 25 & 15 & 4500 \\
\hline Lagadar & 20 & 15 & 10 & 4000 \\
\hline Demand (Butir) & 7000 & 5000 & 3000 & 15000 \\
\hline
\end{tabular}

Berdasarkan seluruh data yang telah dikumpulkan kemudian diformulasikan kedalam model matematis sebagai berikut:

$\min Z=\sum_{i=1, j=1}^{m, n} C i j . X i j$

Minimum $Z=15 X_{11}+20 X_{12}+10 X_{13}+25 X_{21}+25 X_{22}+15 X_{23}+20 X_{31}+15 X_{32}+10 X_{33}$

Batasan Masalah

$X_{11}+X_{12}+X_{13}=6500$

$X_{21}+X_{22}+X_{23}=4500$ 
Jurnal Lebesgue: Jurnal Ilmiah Pendidikan Matematika, Matematika dan Statistika

Dandi Nurdiansyah, Diva Maulana, Artia Tresnadi, Muchammad Fauzi

Volume 2, No. 3, Desember 2021 hal.234-244

DOI Artikel: 10.46306/lb.v2i3.77

$X_{31}+X_{32}+X_{33}=4000$

$X_{11}+X_{21}+X_{31}=7000$

$X_{12}+X_{22}+X_{23}=5000$

$X_{13}+X_{23}+X_{33}=3000$

$\mathrm{X}_{11}, \mathrm{X}_{12}, \mathrm{X}_{13}, \mathrm{X}_{21}, \mathrm{X}_{22}, \mathrm{X}_{23}, \mathrm{X}_{31}, \mathrm{X}_{32}, \mathrm{X}_{33} \geq 0$

Data tersebut kemudian dilakukan pengelolaan menggunakan metode North West Corner sebagai solusi awal. Pengelolaan yang telah dilakukan adalah dapat dilihat pada tabel 4 dan tabel 5 berikut:

Tabel 4. Matriks Biaya Transportasi Dari Sumber Ke Tujuan (dalam rupiah)

\begin{tabular}{|c|c|c|c|c|}
\hline & \multicolumn{3}{|c|}{ Tujuan Pengiriman } & \multirow{2}{*}{$\begin{array}{l}\text { Supply } \\
\text { (butir) }\end{array}$} \\
\hline & Pasar Ciroyom (Rp/butir) & Pasar Caringin (Rp/butir) & Pasar Antri (Rp/butir) & \\
\hline \multirow{2}{*}{ Cimahi } & 15 & 20 & 10 & \multirow[b]{2}{*}{6500} \\
\hline & & & & \\
\hline \multirow{2}{*}{ Batujajar } & 25 & 25 & 15 & \multirow[b]{2}{*}{4500} \\
\hline & & & & \\
\hline \multirow{2}{*}{ Lagadar } & 20 & 15 & 10 & \multirow[b]{2}{*}{4000} \\
\hline & & & & \\
\hline Demand (butir) & 7000 & 5000 & 3000 & 15000 \\
\hline
\end{tabular}

Tabel 5. Hasil Matriks Transportasi North West Corner

\begin{tabular}{|c|c|c|c|c|c|c|c|}
\hline & \multicolumn{6}{|c|}{ Tujuan Pengiriman } & \multirow{2}{*}{$\begin{array}{l}\text { Supply } \\
\text { (butir) }\end{array}$} \\
\hline & Pasar Cir & (p/butir) & \multicolumn{2}{|c|}{ Pasar Caringin (Rp/butir) } & \multicolumn{2}{|c|}{ Pasar Antri (Rp/butir) } & \\
\hline \multirow{2}{*}{ Cimahi } & \multirow[b]{2}{*}{6500} & \multirow[t]{2}{*}{15} & & 20 & & 10 & \\
\hline & & & & & & & 6500 \\
\hline \multirow{2}{*}{ Batujajar } & & 25 & \multirow[b]{2}{*}{4000} & 25 & & 15 & \multirow[b]{2}{*}{4500} \\
\hline & 500 & & & & & & \\
\hline \multirow{2}{*}{ Lagadar } & & 20 & \multirow[b]{2}{*}{1000} & 15 & \multirow[b]{2}{*}{3000} & 10 & \multirow[b]{2}{*}{4000} \\
\hline & & & & & & & \\
\hline Demand (butir) & \multicolumn{2}{|c|}{7000} & \multicolumn{2}{|c|}{5000} & \multicolumn{2}{|c|}{3000} & 15000 \\
\hline
\end{tabular}

Hasil pengelolaan data menggunakan metode North West Corner yang dilakukan hingga iterasi 1 didapatkan solusi awal untuk menentukan jumlah biaya pengiriman. Alokasi pada matriks menggunakan metode North West Corner adalah sebagai berikut:

$X_{11}=6500, X_{12}=0, X_{13}=0, X_{21}=500, X_{22}=4000, X_{23}=0, X_{31}=0, X_{32}=1000$, dan $X_{33}=$ 1000 
Jurnal Lebesgue: Jurnal Ilmiah Pendidikan Matematika, Matematika dan Statistika

Dandi Nurdiansyah, Diva Maulana, Artia Tresnadi, Muchammad Fauzi

Volume 2, No. 3, Desember 2021 hal.234-244

DOI Artikel: 10.46306/lb.v2i3.77

Biaya pengiriman dapat dihitung menggunakan persamaan berikut:

$O T=\sum_{i=1, j=1}^{m, n} C i j . X i j$

$\mathrm{OT}=15 \mathrm{X}_{11}+20 \mathrm{X}_{12}+10 \mathrm{X}_{13}+25 \mathrm{X}_{21}+25 \mathrm{X}_{22}+15 \mathrm{X}_{23}+20 \mathrm{X}_{31}+15 \mathrm{X}_{32}+10 \mathrm{X}_{33}$

$\operatorname{Min} z=15(6500)+20(0)+10(0)+25(500)+25(4000)+15(0)+20(0)+15(1000)+10(3000)$

$\operatorname{Min} \mathrm{z}=\operatorname{Rp} 255.000$

Hasil perhitungan menggunakan metode North West Corner didapatkan hasil biaya transportasi toko Ayam Sehat.com adalah Rp 255.000. Hasil tersebut dikategorikan sebagai hasil perhitungan solusi awal. Diperlukan perhitungan menggunakan Software Lingo untuk mengetahui hasil akhir yang paling optimal. Berikut adalah hasil perhitungan optimal menggunakan Software Lingo:

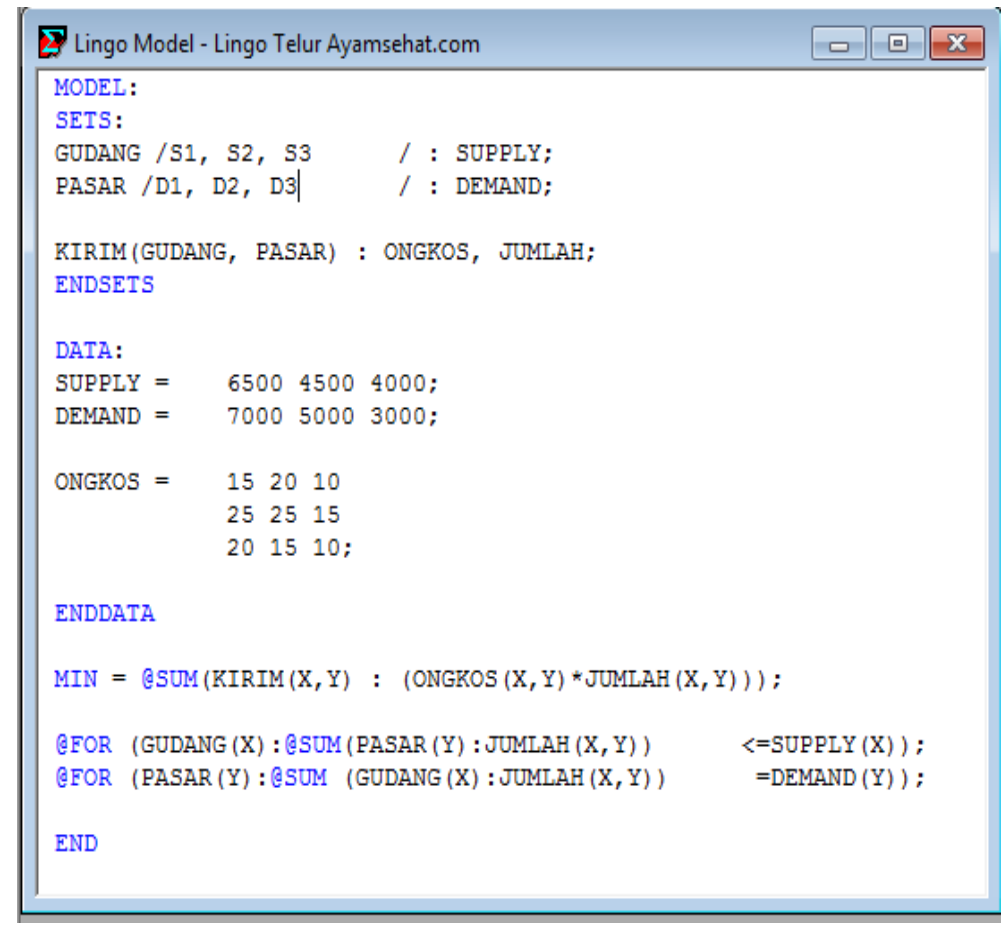

Gambar 1. Syntax Lingo Toko Ayam Sehat.com 
Jurnal Lebesgue: Jurnal Ilmiah Pendidikan Matematika, Matematika dan Statistika

Dandi Nurdiansyah, Diva Maulana, Artia Tresnadi, Muchammad Fauzi

Volume 2, No. 3, Desember 2021 hal.234-244

DOI Artikel: 10.46306/lb.v2i3.77

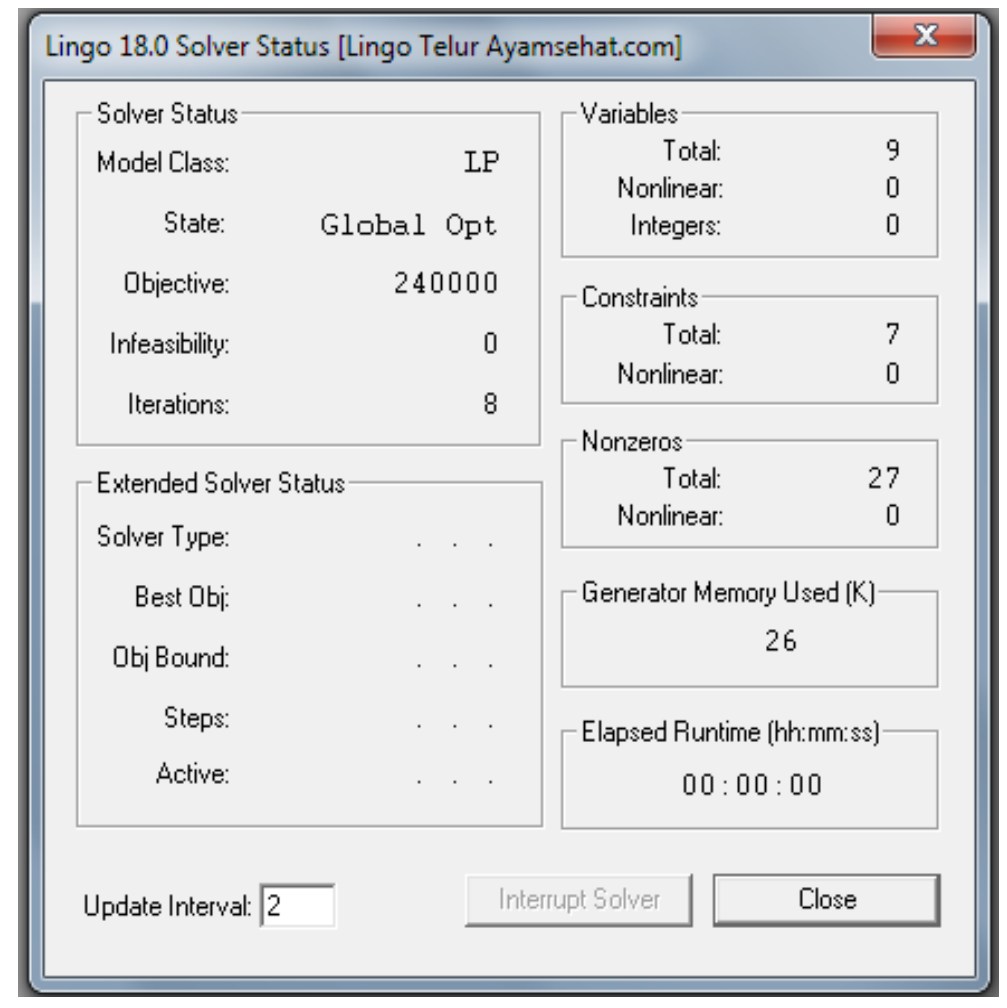

Gambar 2. Status Solusi Menggunakan Software Lingo

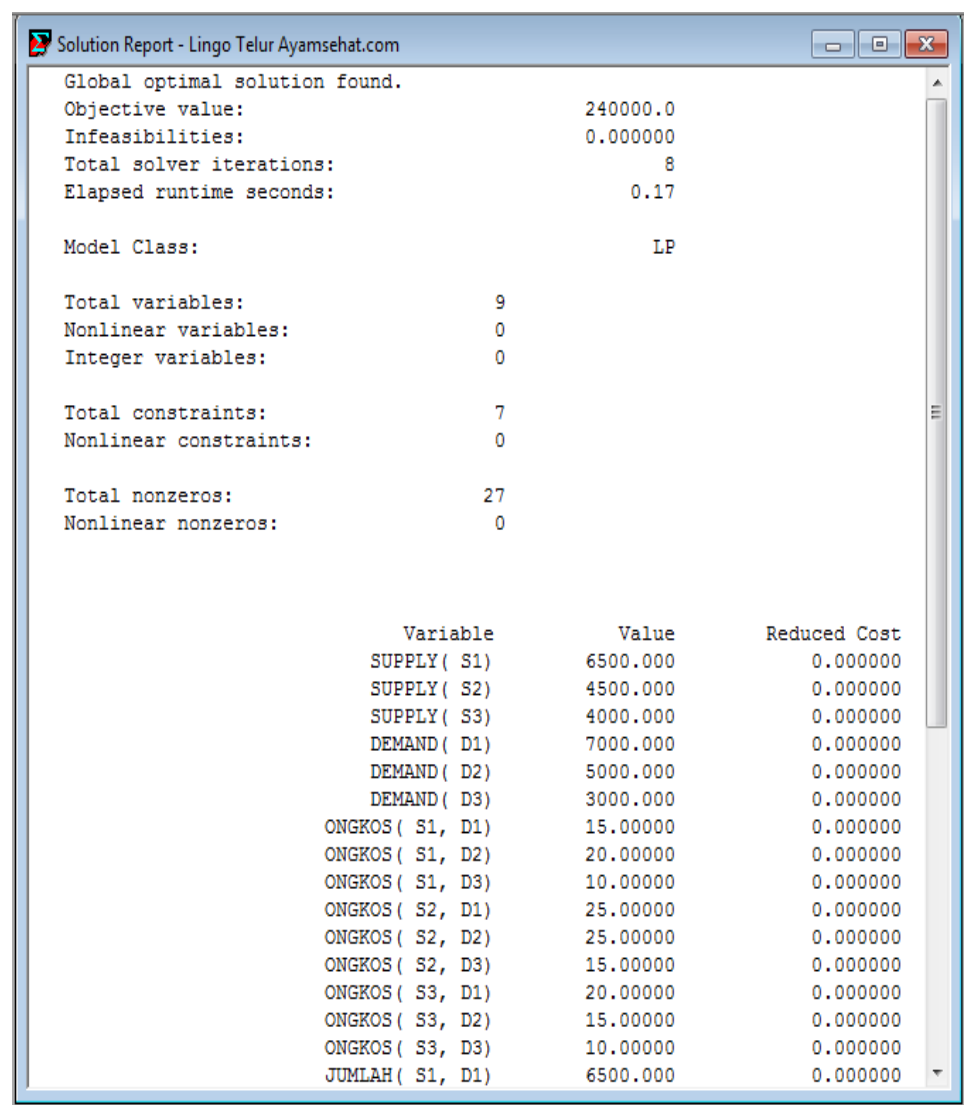

Gambar 3. Hasil Solusi Optimal Bagian 1 


\begin{tabular}{|c|c|c|c|}
\hline \multicolumn{2}{|l|}{ S Solution Report - Lingo Telur Ayamsehat.com } & \multicolumn{2}{|c|}{$\square \square$} \\
\hline Variable & Value & Reduced Cost & A \\
\hline SUPPLY ( S1) & 6500.000 & 0.000000 & \\
\hline SUPPLY( S2) & 4500.000 & 0.000000 & \\
\hline SUPPLY( S3) & 4000.000 & 0.000000 & \\
\hline DEMAND ( D1) & 7000.000 & 0.000000 & \\
\hline DEMAND（D2） & 5000.000 & 0.000000 & \\
\hline DEMAND（D3) & 3000.000 & 0.000000 & \\
\hline ONGKOS(S1， D1) & 15.00000 & 0.000000 & \\
\hline ONGKOS( S1， D2) & 20.00000 & 0.000000 & \\
\hline ONGKOS( S1, D3) & 10.00000 & 0.000000 & \\
\hline ONGKOS ( S2, D1) & 25.00000 & 0.000000 & \\
\hline ONGKOS( S2, D2) & 25.00000 & 0.000000 & \\
\hline ONGKOS( S2， D3) & 15.00000 & 0.000000 & - \\
\hline ONGKOS( S3, D1) & 20.00000 & 0.000000 & \\
\hline ONGKOS( S3, D2) & 15.00000 & 0.000000 & \\
\hline ONGKOS( S3, D3) & 10.00000 & 0.000000 & \\
\hline JUMLAH（S1，D1) & 6500.000 & 0.000000 & \\
\hline JUMLAH ( S1, D2) & 0.000000 & 5.000000 & \\
\hline JUMLAH（S1，D3) & 0.000000 & 5.000000 & \\
\hline JUMLAH（S2，D1) & 500.0000 & 0.000000 & \\
\hline JUMLAH（S2，D2) & 1000.000 & 0.000000 & \\
\hline JUMLAH（S2，D3) & 3000.000 & 0.000000 & \\
\hline JUMLAH（S3，D1) & 0.000000 & 5.000000 & $\equiv$ \\
\hline JUMLAH ( S3, D2) & 4000.000 & 0.000000 & \\
\hline JUMLAH ( S3, D3) & 0.000000 & 5.000000 & \\
\hline Row & Slack or Surplus & Dual Price & \\
\hline 1 & 240000.0 & -1.000000 & \\
\hline 2 & 0.000000 & 10.00000 & \\
\hline 3 & 0.000000 & 0.000000 & \\
\hline 4 & 0.000000 & 10.00000 & \\
\hline 5 & 0.000000 & -25.00000 & \\
\hline 6 & 0.000000 & -25.00000 & \\
\hline 7 & 0.000000 & -15.00000 & - \\
\hline
\end{tabular}

Gambar 4. Hasil Solusi Optimal Bagian 2

Biaya pendistribusian telur ayam dari setiap gudang ke setiap pasar tujuan dilakukan pengoptimalan kembali menggunakan Software Lingo. Hasil perhitungan menggunakan Software Lingo menunjukan bahwa solusi optimal biaya transportasi telur ayam dari setiap gudang ke setiap pasar tujuan adalah sebesar $\mathrm{Rp}$ 240.000. Lebih rendah $\mathrm{Rp} 15.000$ dibandingkan hasil menggunakan metode North West Corner.

\section{KESIMPULAN}

Model biaya transportasi dapat dilakukan dengan menggunakan metode North West Corner $(N W C)$ dan Software Lingo sebagai perbandingan dalam menentukan nilai optimasi biaya pengiriman telur ayam toko Ayam Sehat.com ke setiap pasar tujuan. Perbandingan hasil perhitungan menggunakan kedua metode tersebut dapat dilihat pada tabel 6 dibawah ini: 
Jurnal Lebesgue: Jurnal Ilmiah Pendidikan Matematika, Matematika dan Statistika

Dandi Nurdiansyah, Diva Maulana, Artia Tresnadi, Muchammad Fauzi

Volume 2, No. 3, Desember 2021 hal.234-244

DOI Artikel: 10.46306/lb.v2i3.77

Tabel 6. Perbandingan Hasil Perhitungan

\begin{tabular}{lc}
\multicolumn{1}{c}{ Metode } & Hasil Perhitungan \\
\hline North West Corner & $\mathrm{Rp} \mathrm{255.000}$ \\
\hline Software Lingo & $\mathrm{Rp} \mathrm{240.000}$
\end{tabular}

Dari hasil perhitungan menggunakan kedua metode dapat disimpulkan bahwa biaya optimasi pengiriman telur ayam dari gudang ke setiap pasar tujuan dengan menggunakan metode North West Corner (NWC) sebagai solusi awal adalah sebesar Rp 255.000 untuk pengiriman pada bulan Januari 2021. Sedangkan, dengan menggunakan Software Lingo dilakukan sebagai solusi akhir biaya pengiriman telur ayam dari gudang ke pasar tujuan adalah sebesar Rp. 240.000. Solusi layak atau solusi optimal dalam perhitungan biaya transportasi untuk pengiriman telur ayam toko Ayam Sehat.com adalah menggunakan Software Lingo. Berdasarkan hasil tersebut toko ayam sehat.com dapat mengoptimalkan biaya pendistribusian telur ayam sebesar Rp 38.000 dengan menggunakan metode transportasi.

\section{DAFTAR PUSTAKA}

Ika Widya Ardhyani. 2017. "Mengoptimalkan Biaya Distribusi Pakan Ternak Dengan Menggunakan Metode Transportasi (Studi Kasus di PT. Krian)”. Teknika: Engineering and Sains Journal Volume 1, Nomor 2, Desember 2017, 95-100

Sulistyorini Rahayu. 2014. Perancanaan Dan Permodelan Transportasi. Yogyakarta: Graha Ilmu.

Mulyati, E., and Aghitsna, A., I. (2014). Perencanaan Tarif Ideal Pengiriman Barang Berdasarkan Metode Perhitungan Biaya Operasional Kendaraan (BOK), Politeknik Pos Indonesia.

Penggunaan software LINGO dalam Riset Operasi Masalah Transportasi, diperoleh Juni 12, 2021, dari https://www.youtube.com/watch?v=jUUV7jd9w9k\&t=558s

Permatasari, D, (2015)., Optimasi Distribusi Gula Merah pada UD Sari Bumi Raya Menggunakan Model Transportasi, Universitas Dian Nuswantoro, Semarang.

Widya, I, (2017). Mengoptimalkan Distribusi Pakan Ternak dengan Menggunakan Metode Transportasi, Universitas Maarif Hasyim Latif. Zaroni., Transportasi dalam Rantai Pasok dan Logistik, Supply Chain Indonesia, 2015.

Fatimah, N. L., \& Wibawanto, H., (2015). Implementasi Pengoptimalan Biaya Transportasi dengan North West Corner Method (NWCM) dan Stepping Stone Method (SSM) untuk Distribusi Raskin pada Perum Bulog Sub Drive Semarang, Jurnal Ede Komputika. pp. 4854.

Inc., Lindo System Lingo. 2020. Lingo the modelling language and optimizer.

Gunawan, H. (2014). Pengantar Transportasi dan Logistik. Jakarta: PT RajaGrafindo Persada. 
Jurnal Lebesgue: Jurnal Ilmiah Pendidikan Matematika, Matematika dan Statistika

Dandi Nurdiansyah, Diva Maulana, Artia Tresnadi, Muchammad Fauzi

Volume 2, No. 3, Desember 2021 hal.234-244

DOI Artikel: 10.46306/lb.v2i3.77

Miro, F. (2012). Pengantar Sistem Transportasi. Jakarta: Erlangga.

Putri, I. M. (2018). Minimasi Biaya Distribusi Beras Miskin Dengan Metode NWC Pada Perum Bulog Di Surakarta. Teknologi Informasi Terapan, Vol.16 No.1.

Sutarman. (2017). Dasar-Dasar Manajemen Logistik. Bandung: Refika Aditama. 